\title{
Prevalence of Diarrhoea among Infants of Child Welfare Clinics at Two Teaching Hospitals in Lagos, Nigeria
}

\author{
UBOSI, NI \\ Department of Public Health, National Open University of Nigeria Head Quarters \\ Corresponding Author Email: ihuaguy@yahoo.com
}

\begin{abstract}
The study assessed the prevalence of diarrhoea among infants of Child Welfare Clinics at two University Teaching Hospitals using a semi-structured questionnaire to collect information from mothers on socioeconomic characteristics, infant care practices and diarrhoeal experience of mothers with their infants. Data were analyzed using the Statistical Package for Social Science Software (SPSS version 16.0) in frequencies, percentages and Pearson correlation at $5 \%$ level of significance. The result revealed that prevalence of diarrhoea was high; however the frequency was low with the practice of exclusive breastfeeding and Pearson correlation value of 0.11 . Nevertheless, there was significance association between prevalence of diarrhoea and exclusive breastfeeding (EBF) practice at $\mathrm{P}$-value $<0.05$. There was also a moderate association between the prevalence of diarrhoea and toilet/kitchen water supply with the Pearson correlation value of 0.41 and there was positive relationship between the toilet and kitchen water supply at Pvalue $<0.05$. The frequency of diarrhoea in the two teaching hospitals was low on both exclusively breastfed infants and those who had regular water supply in their kitchen and toilet; ensuring regular availability of potable water and developing policies that promote exclusive breastfeeding practice is essential.
\end{abstract}

\section{DOI: https://dx.doi.org/10.4314/jasem.v22i10.31}

Copyright: Copyright $(\odot) 2018$ Ubosi. This is an open access article distributed under the Creative Commons Attribution License (CCL), which permits unrestricted use, distribution, and reproduction in any medium, provided the original work is properly cited.

Dates: Received: 02 October2018; Revised: 26 October 2018; Accepted 31 October 2018

Keywords: Diarrhoea, Infant, Mothers, Exclusive breastfeeding.

Diarrhoea is among the many signs of stomach problems which presents as frequent loose stools that differ in appearance (WHO, 2018). It can also be defined as the frequent passing of watery or loose stools, more often than that of a normal person under the same situation. According to Dairo et al., (2017) regular passage of formed stools is not diarrhoea. Exclusively breast fed infants pass loose but pasty stools; this however is not regarded as diarrhoea (Dairo et al., 2017). Submission by Fonyuy (2014) revealed that $80 \%$ of all the sicknesses in third world countries are secondary to water-borne infection which diarrhoea leading to dehydration as the principal cause of infantile mortality is included. Diarrhoeal disease has been classified as a prominent killer of kids, which has been implicated for roughly eight per cent of all mortality among youngsters below 5 years of age globally. Invariably this leads to the death of more than one thousand three hundred youngsters daily, or approximately four hundred and eighty thousand children in a year, notwithstanding the effectiveness of the easy accessible treatment (UNICEF, 2018). Amongst the most common diarrhoeal diseases are Cholera, typhoid fever and hepatitis A which are caused by bacteria. Some other diarrhoeal infections, for instance dysentery, are secondary to parasitic infections that reside in water which is contaminated by human faeces. Recent research has indicated water-borne disease as a prominent cause of greater than 3.4 million peoples' death and sickness yearly across the globe (WHO, 2009). Dehydration that resulted from the reduction in numerous quantities of electrolytes from any of spewing or profuse diarrhoea is the foremost indicator and cause of death from infections that come from water contamination (Fonyuy, 2014). Majority of the death from diarrhoea occur amongst children under two residing in South Asia and sub-Saharan Africa. However, there had been progress, between year 2000 and 2016, the total annual number of deaths from diarrhoea among children below five years reduced by $60 \%$ (UNICEF, 2018). Despite initiating substantial death and ill health, diarrhoea had been established as the foremost reason for under-five years' old children malnutrition due to its relationship with inadequate nutrient absorption and decrease in appetite. Recurrent episodes of severe diarrhoea extremely incapacitate children. There is usually a reduction in weight of the child following each diarrhoeal session, thus predisposing them to malnourishment and reduced growth (Dairo et al., 2017). This study was designed to determine the 
prevalence of diarrhoea among infants of Child Welfare Clinics at two University Teaching Hospitals in Lagos.

\section{MATERIALS AND METHOD}

Study Area: Lagos is the former capital of Nigeria, the largest commercial city in Nigeria, and one of Africa's fastest growing cities. It is a cosmopolitan city and has the greatest concentration of manufacturing and service industries owing to the advantages offered by seaports and international airport. Lagos is highly congested, and hence there has been vigorous suburban development and intense competition for sites between industry, housing, commerce, and public utilities. Being a cosmopolitan city the residents are known for busy schedule that exposes them to food prepared by food vendors or eateries which could be contaminated. The study was conducted in two (2) Teaching Hospitals in Lagos. It was a descriptive cross sectional study among mothers of infants below 6 months who were attending Child Welfare Clinic in these Teaching Hospitals. All the mothers of infants below 6 months (202) that came for Child Welfare Clinic in the two Teaching Hospitals between January and March 2018 were interviewed. Pretested interviewer administered questionnaires were used to collect data between January and March 2018 with the assistance of a qualified nurse and a research assistant. The questionnaire sought information on the socio demo-graphic characteristics, mothers' hygiene habits, infant feeding practice and frequency of diarrhoea.

Ethical Approval: Permission was taken from the Management of the Teaching Hospitals. A verbal informed consent was obtained from the mothers and privacy and confidentiality were assured.

Data were analyzed using the Statistical Package for Social Science Software (SPSS version 16.0) in frequencies, percentages and Pearson correlation. Chi square was used to determine relationships and statistically significant level was taken at $\mathrm{p}$ value < 0.05 .

\section{RESULTS AND DISCUSSION}

Socio Demo-graphic Characteristics: The respondents were aged between 18 and 43 years; those married $(75.8 \%)$ were in the majority, $20 \%$ had primary education, $44 \%$ had secondary education while $36 \%$ had tertiary education. The babies were aged between 0- 6 months. Majority of the respondents were living on less than 100,000 naira a month. Standard of living is determined by family income and this study revealed that majority of the families under study had family income between 10,000 and 100,000 naira predominantly which is low compared to the high cost of living in Lagos. This is in line with the findings of Mamo et al., (2014); Nwaoha et al.(2017) who identified a significant relationship with frequency of diarrhoea and socioeconomic status of an individual. The reason for this result is not far-fetched; generally, wealth creates good opportunity to acquire household facilities and comfort, as well as those needed to maintain and promote good environmental health and hygiene that could decrease diarrhoeal predisposition. In agreement Marmot (2015) stated that many other studies indicated that socioeconomic factors are strongly associated with the occurrence of diarrhoea; this appears to confirm the social determinants of health.

Infant Care Practices of Mothers Attending the Child Welfare Clinics at the two University Teaching Hospitals in Lagos: Table 1 showed the infant care practices of mothers attending the Child Welfare Clinics at the two University Teaching Hospitals in Lagos. Many mothers $(62.4 \%)$ practiced exclusive breastfeeding, while $37.6 \%$ did not. Some of the respondents $(56.4 \%)$ fed their babies directly on breast, some $35.6 \%$ fed their babies with feeding bottles and only $8.0 \%$ were fed with cup and spoon. Some percentage of non-breast fed infants (19.8\%) was feeding on infant formula while $15.8 \%$ of them were being fed with pap; only $2 \%$ received glucose. More than half of the respondents $(64.3 \%)$ had the knowledge of the benefits of adequate breastfeeding while $34.7 \%$ did not have such knowledge. Majority $(76.0 \%)$ of the mothers fed their babies by themselves; a few $(16.0 \%)$ of the respondents stated that their babies were fed by anybody available; only $7.9 \%$ of the babies were fed by nanny or housemaid. Majority $(92.0 \%)$ of the children had completed immunization; while only $8.0 \%$ had not completed immunization. Majority $(94.1 \%)$ of the mothers said that they usually wash their hands after cleaning baby's diapers while very few $(5.9 \%)$ do not wash their hands after cleaning their baby's diapers. Almost all (96\%) of the mothers were still breastfeeding their children while very small percentage $(4 \%)$ were no longer breastfeeding their babies. The prevalence of diarrhoea was highest $(62.4 \%)$ among 5-6 months age group. This finding is in contrast to results from a study in Burkina Faso, where children under the age of 3 months had the highest rate of diarrhoea (44\%) (Nitiema et al., 2011). It was found that diarrhoea prevalence was high; however, the frequency was low among children whose mothers practiced exclusive breastfeeding which is consistent with the findings of Ahs et al. (2010). 
Table 1: Infant Care Practices of Mothers Attending Child Welfare Clinics at two University Teaching Hospitals in Lagos (N=202)

\begin{tabular}{|c|c|c|c|}
\hline Parameters & Variables & Frequency & Percentages \\
\hline \multirow[t]{2}{*}{$\begin{array}{l}\text { Practice of } \\
\text { breastfeeding }\end{array}$} & Yes & 126 & 62.4 \\
\hline & No & 76 & 37.6 \\
\hline \multirow[t]{3}{*}{ Feeding method } & Feeding bottle & 72 & 35.6 \\
\hline & Cup and spoon & 16 & 78.0 \\
\hline & Direct on breast & 114 & 56.4 \\
\hline \multirow{4}{*}{$\begin{array}{l}\text { Feeding practice of none } \\
\text { EBF }\end{array}$} & Pap & 32 & 15.8 \\
\hline & Glucose & 4 & 2.0 \\
\hline & Infant formulae & 40 & 19.8 \\
\hline & Practice EBF & 126 & 62.4 \\
\hline \multirow{3}{*}{$\begin{array}{l}\text { Knowledge of the benefit of } \\
\text { EBF }\end{array}$} & Yes & 130 & 64.3 \\
\hline & No & 70 & 34.7 \\
\hline & No response & 2 & 1.0 \\
\hline \multirow[t]{3}{*}{ Who feeds the baby } & Mother & 154 & 76.0 \\
\hline & Nanny & 16 & 8.0 \\
\hline & Others & 32 & 16.0 \\
\hline \multirow{2}{*}{$\begin{array}{l}\text { Immunization status of the } \\
\text { baby }\end{array}$} & Completed & 186 & 92.0 \\
\hline & Uncompleted & 16 & 8.0 \\
\hline \multirow{2}{*}{$\begin{array}{l}\text { Wash hands after change of } \\
\text { Diaper }\end{array}$} & Yes & 190 & 94.1 \\
\hline & No & 12 & 5.9 \\
\hline \multirow[t]{2}{*}{ Breastfeeding status } & Still breastfeeding & 194 & 96.0 \\
\hline & Not breastfeeding & 8 & 4.0 \\
\hline
\end{tabular}

Table 2: Diarrhoeal Experience of the Mothers with their Infants

\begin{tabular}{|c|c|c|c|}
\hline Parameters & Variables & Frequency & Percentages \\
\hline \multirow[t]{3}{*}{ Frequency of Diarrhoea } & Once & 60 & 29.7 \\
\hline & Twice & 16 & 8.0 \\
\hline & Trice & 126 & 62.3 \\
\hline \multirow{3}{*}{$\begin{array}{l}\text { Age of diarrhea } \\
\text { experience }\end{array}$} & $0-1$ & 8 & 4.0 \\
\hline & $3-4$ & 68 & 33.7 \\
\hline & $5-6$ & 126 & 62.3 \\
\hline \multirow[t]{3}{*}{$\begin{array}{l}\text { Where treatment was } \\
\text { given }\end{array}$} & At home & 62 & 30.7 \\
\hline & Hospital & 138 & 68.3 \\
\hline & Others & 2 & 1.0 \\
\hline \multirow[t]{3}{*}{ Baby's Age } & $0-2 \mathrm{mnts}$ & 28 & 13.8 \\
\hline & $3-4 \mathrm{mnts}$ & 66 & 32.7 \\
\hline & $5-6 \mathrm{mnts}$ & 108 & 53.5 \\
\hline \multirow[t]{3}{*}{ Sterilization method } & Milton solution & 104 & 51.5 \\
\hline & Salt and water solution & 62 & 30.7 \\
\hline & wash with soap and water & 36 & 17.8 \\
\hline \multirow[t]{3}{*}{ Hand Wash Frequency } & As soon as possible & 50 & 24.8 \\
\hline & After change of diaper & 116 & 57.4 \\
\hline & When water is available & 36 & 17.8 \\
\hline \multirow[t]{3}{*}{ Source of water } & Well & 64 & 31.7 \\
\hline & Borehole & 102 & 50.5 \\
\hline & Buy from mallam & 36 & 17.8 \\
\hline \multirow[t]{3}{*}{ Type of toilet at home } & Pit latrine & 40 & 19.8 \\
\hline & Water closet toilet & 160 & 80.2 \\
\hline & Use the nearest bush & 2 & 1.0 \\
\hline \multirow[t]{2}{*}{ Water availability } & $\begin{array}{l}\text { water runs inside my } \\
\text { house }\end{array}$ & 104 & 51.5 \\
\hline & No water inside my house & 98 & 48.5 \\
\hline \multirow[t]{4}{*}{ Type of accommodation } & Face me I face you & 86 & 42.6 \\
\hline & Flats & 102 & 50.5 \\
\hline & Duplex & 12 & 5.9 \\
\hline & Others & 2 & 1.0 \\
\hline \multirow{4}{*}{$\begin{array}{l}\text { Method } \\
\text { disposal }\end{array}$} & PSP & 162 & 80.1 \\
\hline & Burning & 30 & 14.9 \\
\hline & Burying & 8 & 4.0 \\
\hline & others & 2 & 1.0 \\
\hline
\end{tabular}

This is also in line with the submissions of Sankar et al., (2015); WHO (2013) that one of the many benefits of ideal breast feeding include lower risk for infectious diseases such as diarrhoea.

Diarrhoeal Experience of the Mothers with their Infants: Table 2 represents diarrhoeal experience of the mothers with their infants at the two teaching hospitals. More than half $(62.3 \%)$ had diarrhoeal experience trice; a few $(8.0 \%)$ had it twice while some $(29.7 \%)$ had diarrhoeal experience once. A small percentage (4\%) had diarrhoea experience at one month of age; some (33.6\%) had diarrhoeal experience at 3 to 4 months of age and as many as $62.4 \%$ had it at 5 to 6 months. Some $(30.7 \%)$ of the diarrhoea cases were treated at home, more than half $(68.3 \%)$ at the hospital and only one percent (1\%) was treated elsewhere. A few $(13.8 \%)$ of the babies were between 0-2 months, some $(32.7 \%)$ were between 3-4months and a little above half $(53.5 \%)$ were between 5 6 months. About half $(51.5 \%)$ of the mothers used Milton solution methods for sterilization, some (30.7\%) used salt and water solution for sterilization and a few percentages $(17.8 \%)$ did not use any known method for sterilization, they just washed with soap and water. Some of the mothers (24.8\%) washed their hands as often as possible; more than half $(57.4 \%)$ of the mothers washed their hands after change of diapers while a small percentage $(17.8 \%)$ washed their hands only when water was available. Some $(31.7 \%)$ of the mothers used well as their main source of water, a little above half $(50.5 \%)$ used borehole and a few (17.8\%) bought from Mallam. A few $(19.8 \%)$ used pit latrine at home, most $(80.2 \%)$ used water closet and only one percent of (1\%) the respondents used nearby bush. About $(51.5 \%)$ of the mothers had water run into their house (toilet and 
kitchen) and a little below half (48.5\%) did not have water run into their toilet and kitchen. About $42.6 \%$ of the mothers live in face me and I face you house, about half $(50.5 \%)$ live in flats, very little (5.9\%) were living in duplexes and only one percent $(1 \%)$ were living in others kind of houses. Most $(81 \%)$ of the mothers used PSP (Proper Sewage disposal Practice) to dispose their waste; $15 \%$ disposed theirs through burning and while only a few (4\%) bury their waste. Households with regular water supply will have improved sanitary conditions against diarrhoea. This agrees with the findings that improved hygienic atmosphere and availability of potable water to households helps to reduce diarrhoeal disease (Ogbo et al., 2017).

Table 3: Relationship Between The Prevalence of Diarrhoea, Practice of Exclusive Breastfeeding and Toilet and Kitchen Water Supply.

\begin{tabular}{|c|c|c|c|c|c|}
\hline & & prevalence & of & diarrhoea & \\
\hline Variables & & Once & Twice & Thrice & T otal \\
\hline Exclusive & Yes & 36 & 70 & 20 & 126 \\
\hline Breastfeeding Practice & No & 14 & 46 & 16 & 76 \\
\hline $\begin{array}{l}\text { Level of significance } \\
\text { Pearson correlation } \\
\text { /value }\end{array}$ & & $0.025 / 0.11$ & $0.025 / 0.11$ & $0.025 / 0.11$ & 202 \\
\hline $\begin{array}{l}\text { Toilet and Kitchen } \\
\text { water supply }\end{array}$ & $\begin{array}{l}\text { Yes } \\
\text { No }\end{array}$ & $\begin{array}{l}36 \\
14\end{array}$ & $\begin{array}{l}66 \\
50\end{array}$ & $\begin{array}{l}2 \\
34\end{array}$ & $\begin{array}{l}104 \\
98\end{array}$ \\
\hline $\begin{array}{l}\text { Level of significance } \\
\text { Pearson correlation } \\
\text { /value }\end{array}$ & & $0.00 / 0.41$ & $0.00 / 0.41$ & $0.00 / 0.41$ & 202 \\
\hline
\end{tabular}

Relationship between Prevalence of Diarrhoea, Practice of Exclusive Breast Feeding and Toilet and Kitchen Water Supply: Table 3 showed that frequency of diarrhoea was low with the practice of exclusive breastfeeding and Pearson correlation value of 0.11 but there was significance association between prevalence of diarrhoea and exclusive breastfeeding practice at $\mathrm{P}$-value $<0.05$. There was also a moderate association between the prevalence of diarrhoea; toilet and kitchen water supply with Pearson correlation value of 0.41 and there was positive relationship between the toilet and kitchen water supply at P-value $<0.05$. Reducing childhood diarrhoea requires interventions to make children healthier and less likely to develop infections that lead to diarrhoea; clean environments are less likely to transmit disease. Evidence indicates that appropriate water, hygiene, and sanitation interventions can reduce diarrhoea incidence by $26 \%$ and mortality by 65\% (Cairncross et al., 2010).

Conclusion: The prevalence of diarrhoea among the infants of Child Welfare Clinics at the two University Teaching Hospitals was high; however, the frequency was low on both exclusively breastfed infants and those who had regular water supply in their kitchen and toilet. Promoting exclusive breast feeding, good hygiene habits and also highlighting the importance of a regular supply of safe drinking water through health education in the health centres and hospitals is imperative.

\section{REFERENCES}

Ahs, JW; Tao, W; Lofgren, J; Forsberg Birger, C (2010). Diarrhoeal diseases in low-and middleincome countries: incidence, prevention and management. Open Infectious Diseases Journal. $4(1): 113-24$.

Cairncross, S; Hunt, C; Boisson, S (2010). Water, sanitation and hygiene for the prevention of diarrhoea. International Journal of Epidemiology, 39:i193-i205 doi:10.1093.

Dairo, MD; Ibrahim, TF; Salawu, AT (2017). Prevalence and determinants of diarrhoea among infants in selected primary health centres in Kaduna north local government area, Nigeria. Pan Afr Med J.; 28:109 doi: 10.11604/pamj.2017.28.109.8152.

Mamo, A; Hailu, A (2014). Assessment of prevalence and related factors of diarrhoeal diseases among under-five year's children in Debrebirehan referral hospital, Debrebirehan town, north Shoa zone, Amhara region, Ethiopia. Open Access Library Journal, 1:e283.

Marmot, M (2015). The health gap: the challenge of an unequal world. Lancet; 386(110011):2442-4. doi: 10.1016/S0140-6736(15)00150-6.

Nitiema, LW; Nordgren, J; Ouermi, D; Dianou, D; Traore, AS; Svensson, L (2011).Burden of rotavirus and other enteropathogens among children with diarrhoea in Burkina Faso. Int $J$ Infect Dis; 15(9):e646-52.

Nwaoha, FN; Ohaeri, CC; Amaechi, EC (2017). Prevalence of diarrhoea, and associated risk factors, in children aged 0-5 years, at two hospitals in Umuahia, Abia, Nigeria; Cuadernos de Investigación NED vol.9 n.1 Sabanilla, Montes de Oca Jan./Jun. 2017.

Ogbo, FA; Agho, K; Ogeleka, P; Andrew, SW (2017): Infant feeding practices and diarrhoea in sub- Saharan African countries with high diarrhoea mortality Page1,2, John Eastwood 
2,6,7,8,9, Global Child Health Research Interest Group 10 .

Onyuy, BE (2014). Prevalence of Water Borne Diseases within Households in the Bamendankwe Municipality-North West Cameroon. J Biosafety Health Educ 2:122.

Sankar, MJ; Sinha, B; Chowdhury, R; Bhandari, N; Taneja, S; Martines, J (2015). Optimal breastfeeding prac- tices and infant and child mortality: a systematic review and metanalysis. Acta paediatrican. 2015; 104 (S467):3-13.

UNICEF (2018). Diarrhoeal disease: https://data.unicef.org/topic/childhealth/diarrhoeal-disease.
WHO (2009). Drastic consequences of Diarrhoeal diseases. https://www.dandc.eu/en/article/drasticconsequences-diarrhoeal-disease.

WHO (2013). Short-term effects of breastfeeding: a systematic review of the benefits of breastfeeding on diarrhoea and pneumonia mortality Geneva, Switzerland.

WHO (2018). Diarrhoeal disease: WHO fact sheet on diarrhoeal disease provides key facts and information on scope, causes, prevention and treatment, WHO response. 